\title{
AKULTURASI BUDAYA JAWA SEBAGAI STRATEGI DAKWAH
}

\author{
Rina Setyaningsih \\ Institut Agama Islam An Nur Lampung \\ Email: rina.setyaningsih15@gmail.com
}

\begin{abstract}
Culture was inherent in Indonesian society before Islam came. Especially in HinduBuddhist communities, people do not know Islam. Many groups still believe in animismdynamism. Especially the Javanese community that smells mystical is still often done. Culture is divided into three phases namely: Javanese culture pre-Hindu-Buddhist, the prominent feature of the structure of society at that time was based on the rules of customary law and its religious system, namely animism-dynamism which is the core of culture that colors all activities of the lives of the people. Customary law is so binding that the people are static and conservative. Javanese Hindu Culture, In this phase the development process of Javanese culture is a strong influence of Indian culture (Hinduism). In Javanese society, Hindu-Buddhist influences are expansive, while Javanese culture which accepts the influence and absorbs Hinduism-Buddhist elements after going through the acculturation process does not only affect the cultural system, but also affects the religion. And Javanese culture in the phase of spreading and institutionalizing propaganda in Java. In this last phase Islam has entered Indonesia and the community has begun to embrace Islam through propaganda with cultural media so that it can be accepted by all parties.
\end{abstract}

Keywords: Culture, Islam, Kejawen

\begin{abstract}
Abstrak
Budaya sudah melekat dalam masyarakat Indonesia sebelum Islam datang. Terutama di komunitas Hindu-Budha, orang tidak mengenal Islam. Banyak kelompok masih percaya pada animisme-dinamisme. Terutama masyarakat Jawa yang berbau mistis masih sering dilakukan. Budaya dibagi menjadi tiga fase yaitu: budaya Jawa pra-Hindu-Buddha, ciri menonjol dari struktur masyarakat pada waktu itu didasarkan pada aturan hukum adat dan sistem keagamaannya, yaitu animisme-dinamisme yang merupakan inti dari budaya yang mewarnai semua aktivitas kehidupan rakyat. Hukum adat sangat mengikat sehingga masyarakatnya statis dan konservatif. Budaya Hindu Jawa, Pada fase ini proses pengembangan budaya Jawa merupakan pengaruh kuat budaya India (Hindu). Dalam masyarakat Jawa, pengaruh Hindu-Budha bersifat ekspansif, sementara budaya Jawa yang menerima pengaruh dan menyerap unsur-unsur Hindu-Buddha setelah melalui proses akulturasi tidak hanya mempengaruhi sistem budaya, tetapi juga mempengaruhi agama. Dan budaya Jawa dalam fase menyebarkan dan melembagakan propaganda di Jawa. Pada fase terakhir ini Islam telah masuk ke Indonesia dan masyarakat sudah mulai memeluk Islam melalui propaganda dengan media budaya sehingga bisa diterima oleh semua pihak.
\end{abstract}

Kata kunci: Budaya, Islam, Kejawen

\section{A. Pendahuluan}

Ketika Islam belum datang di Indonesia, kebudyaan sudah berkembang bahkan sudah menjadi tradisi bagi beberapa jenis suku di negeri ini, seperti budaya jawa. Kebudayaan jawa sudah ada jauh sebelum Islam datang, 
masyarakat jawa masih mempercayai mistis, mereka beraliran animism dan dinamissme, yang berkeyakinan bahwa nenek moyang adalah pengemongnya, masih banyak tradisi yang dilakukan seperti selametan, ruwatan yang bertujuan untuk meminta keselamatan terhindar dari segala mala petaka. Namunketika Islam datang ke Indonesia dengan proses sedemikian rupa lambat laun masyarakat ikut terbawa dengan kepandaian para wali yang berdakwah dengan melalui kebudayaan salah satunya adalah kesenian pewayangan yang pada akhirnya dapat menarik masyarakat untuk masuk Islam tanpa menghilangkan tradisi terdahulu namun hanya terjadi peralihan sehingga tradisi terdahulu menjadi bernuansa religious. ${ }^{1}$

\section{B. Pembahasan}

\section{Definisi Akulturasi}

Akulturasi merupakan perpaduan antara komponen-komponen kebudayaan yang berbeda dan Bersatu dalam usaha membentuk kebudayaan baru tanpa menghilangkan kepribadian kebudayaan yang asli. Hal ini berbeda dengan asimilasi, definisi asimilasi yakni adanya penggabungan dua kebudayaan baru dan menghilangkan kebudayaan yang lama. Contoh dari akulturasi budaya yaitu semisal adanya perpaduan antara music melayu dengan musik spanyol maka akan tercipta musik keroncong, dimana musik keroncong merupakan bagian dari kedua musik tersebut namun tidak menghilangkan ciri khasnya. Contoh akulturasi di Indonesia yaitu adanya sistem dakwah melalui wayang, seni bangunan masjid dengan atap tumpang yang menunjukkan adanya akulturasi Islam dengan budaya hindu. Peran kebudayaan adalah sebagai berikut :

a. suatu hubungan pedoman antar manusia atau kelompoknya.

b. Wadah untuk menyalurkan perasaan dan kemampuan-kemampuaan lain.

c. Sebagai pembimbing kehidupan dan penghidupan manusia.

d. Pembeda manusia dan binatang.

e. Petunjuk-petunjuk tentang bagaimana manusia harus bertindak dan berprilaku di dalam pergaulan.

f. Pengatur agar manusia dapat mengerti bagaimana harud bertindak, berbuat .

g. Sebagai modal dasar pembangunan. ${ }^{2}$

${ }^{1}$ Limyah Al-Amri And Muhammad Haramain, "Akulturasi Islam Dalam Budaya Lokal," Kuriositas: Media Komunikasi Sosial Dan Keagamaan 10, No. 2 (November 24, 2017): 192, Https://Doi.Org/10.35905/Kur.V10i2.594.

2 Laode Monto Bauto, "Perspektif Agama Dan Kebudayaan Dalam Kehidupan Masyarakat Indonesia (Suatu Tinjauan Sosiologi Agama)," Jurnal Pendidikan Ilmu Sosial 23, No. 2 (2014): 19, Https://Doi.Org/10.17509/Jpis.V23i2.1616. 


\section{Definisi Islam}

Secara harfiah, Islam berarti damai, selamat, tunduk, dan bersih. Maka dapat disimpulkan bahwa Islam adalah agama yang membawa keselamatan hidup di dunia dan di akhirat.

Menurut istilah, Islam adalah ketundukkan seorang hamba kepada wahyu ilahi yang diturunkan kepada para nabi dan rasul khususnya Muhammad saw. Untuk dijadikan pedoman hidup dan sebagai aturan allah swt. Islam juga merupakan agama terakhir yang diturunkan oleh allah kepada nabi Muhammad untuk menuntun umat ke jalan yang lurus dan meraih kebahagiaan di dunia dan juga di akhirat. Nabi Muhammad merupakan rasul terakhir utusan allah berlaku sepanjang zaman serta ajarannya bersumber dari al-qur'an dan sunnah. ${ }^{3}$

\section{Dakwah}

Dakwah berasal dari kata دع د ا يدعو - دعوه yang berarti panggilan, seruan dan ajakan . sedangkan menurut istilah, banyak yang mendefinisikan dakwah. Diantaranya seperti saifudin azhari, menurutnya dakwah adalah segala aktivitas yang mengubah suatu situasi lain yang lebih baik menurut ajaran Islam. Tetapi juga berupa usaha meneruskan dan menyampaikan kepada perorangan dan umat. $^{4}$

\section{Budaya Jawa Sebagai Media Dakwah}

Salah satu media yang digunakan dalam berdakwah adalah dengan menggunakan kulturalisasi atau strategi dakwah dengan kebudayaan sebagai perantara. Berikut ini merupakan fase-fase perkembangan kebudayaan jawa.Dalam fase-fase pertumbuhan kebudayaan jawa bertujuan untuk melihat sejauh mana pergumulan budaya jawa sesudah Islam datang. Dalam hal ini dikaji untuk mengupas sistem serta karakteristik budaya jawa. Berikut ini pertumbuhan budaya jawa.

\section{a. Kebudayaan Jawa Pra-Hindu-Budha}

Ciri yang menonjol dari struktur masyarakat pada waktu itu didasarkan pada aturan-aturan hukum adat serta sistem religinya, yakni animismdinamisme yang merupakan inti kebudayaan yang mewarnai seluruh aktivitas kehidupan masyarakatnya. Hukum adat istiadat yang adat begitu mengikat sehingga masyarakatnya bersifat statis dan konservatif.

Kuatnya ikatan solidaritas sosial dan hubungan pertalian darah merupakan ciri masyarakat Indonesia lama. Dalam masyarakat jawa, pendewaan

${ }^{3}$ Septiana Purwaningrum And Habib Ismail, “Akulturasi Islam Dengan Budaya Jawa: Studi Folkloris Tradisi Telonan Dan Tingkeban Di Kediri Jawa Timur," Fikri : Jurnal Kajian Agama, Sosial Dan Budaya 4, No. 1 (June 14, 2019): 35, Https://Doi.Org/10.25217/Jf.V4i1.476.

${ }^{4}$ Masykurotus Syarifah, "Budaya Dan Kearifan Dakwah," Al-Balagh: Jurnal Dakwah Dan Komunikasi 1, No. 1 (June 8, 2016): 29, Https://Doi.Org/10.22515/Balagh.V1i1.43. 
dan pemitosan terhadap ruh nenek moyang melahirkan penyembahan ruh nenek moyang "ancestor worship" yang menghasilkan adat dan relasi-relasi pendukungnya. Dengan upacara-upacara selametan, ruh nenek moyang menjadi berbentuk dewa pelindung bagi keluarga yang masih hidup.

Seni pewayangan dan gamelan menjadi sarana upacara ritual keagamaan untuk mendatangkan ruh nenek moyang. Dalam ritual seperti ini, nenek moyang berfungsi sebagai 'pengemong' dan pelindung keluarga yang masih hidup. Dalam lakon wayang, ruh nenek moyang di ibaratkan dalam bentuk 'punakawan'. Agama asli mereka disebut sebagai 'religion magic' dan merupakan sistem budaya yang mengakar kuat dalam masyarakat Indonesia, khususnya masyarakat jawa.

Adanya ruh dan kekuatan-kekuatan gaib dipandang sebagai tuhan yang dapat menolong ataupun dapat mencelakakan. Oleh sebab itu, w. Robertson smith menyatakan bahwa upacara religi yang biasa dilakukan masyarakat pada waktu itu berfungsi sebagai motivasi yang dimaksudkan tidak saja untuk berbakti kepadda dewa ataupun untuk mencari kepuasan batiniah yang bersifat individual, tetapi juga karena mereka menganggap melaksanakan upacara agama adalah bagian dari kewajiban sosial.

\section{b. Kebudayaan Jawa Masa Hindu-Budha}

Pada fase ini proses perkembangan budaya jawa adalah adanya pengaruh yang kuat dari budaya india (hindu-budha). Dalam masyarakat jawa, pengaruh hindu-budha bersifat ekspansif, sedangkan budaya jawa yang menerima pengaruh dan menyerap unsur-unsur hinduisme-budhisme setelah melalui proses akulturasi tidak hanya berpengaruh pada sistem budaya, tetapi juga berpengaruh terhadap agama.

Sejak awal, budaya jawa yang dihasilkan pada masa hindu-budha bersifat terbuka untuk menerima agama apapun dengan pemahaman bahwa semua agama itu baik, maka sangatlah wajar jika kebudayaan jawa bersifat sinkretis(bersifat momot atau serba memuat). Agama hindu-budha di negeri asalnya justru saling bermusuhan tetapi keduanya dapat dipersatukan menjadi konsep agama yang sinkretis, yaitu agama 'syiwa budha.

Contoh lain dari budaya jawa pada waktu itu adalah sangat bersifat teokratis. Pengkultusan terhadap raja-raja sebagai titisan dewa adalah salah satu buktinya. Dalam hal ini, onghokham menyatakan : penanaman watak teokratis dan watak supremasi raja kepada rakyatnya melalui media hiburan rakyat, yaitu melalui pementassan wayang. Dalam pertunjukkan wayang, dipaparkan sebagai tatakrama feodal yang halus, dan berlaku di keraton, serta lagu-lagu (tembang) merdu beserta gamelannya. Dalam cerita wayang juga disodorkan pula konsep binathara dengan segala kesaktiannya dan pusaka-pusaka keraton yang berdaya magis. 


\section{c. Penyebaran Dan Pelembagaan Dakwah Di Jawa}

Islam datang, berkembang dan melembaga di nusantara melalui proses yang Panjang. Pergumulan di dalam proses Islamisasi di nusantara sekurangkurangnya menghasilkan empat teori besar tentang dimana, kapan, dan dari mana Islam datang dan berkembang di nusantara.

Pertama, menyatakan bahwa Islam datang dari anak benua india. Teori ini awalnya diperkenalkan oleh G.W.J. Drewes, kemudian dikembangkan oleh snouck hurgronje. Drewes beralasan orang-orang arab bermazhab syafi'I yang menetap di Gujarat dan Malabar, itulah yang mengembangkan Islam di nusantara. Paling tidak, indicator yang jelas adalah terdapat kesamaan antara orang Islam yang menetap di Malabar dan Gujarat dengan orang Islam nusantara.

Kedua, teori yang menyatakan bahwa Islam masuk ke nusantara berassal dari Bengal, sebagaimana diungkapkan oleh S.Q.Fatimi. dia beranggapan bahwa teori batu nisan di makam malik al-shalih sama sekali berbeda dengan makan yang ada di Gujarat. Akan tetapi, batu nisan Fatimah binti maimun di leran jawa timur bertahun 475 H/1082 M,justru memiliki kesamaan batu nisan di Bengal. Teori ini mengandung kelemahan, sebab antara Bengal dan nusantara terdapat perbedaan mazhab, yaitu wilayah di Bengal bermazhab hanafisedangkan muslim di nusantara bermazhab syafi'i.

Ketiga, teori yang menyatakan bahwa Islam datang ke Indonesia melalui colomader dan Malabar. Sejarahwan yang berpendapat demikian adalah Thomas w. Arnold. Ia beralassan wilayah ini memiliki kesamaan mazhab dengan wilayah nusantara waktu itu. Teori ini mendapat dukungan dari morrison. Ia berpendapat, tidak mungkin Islam datang ke nusantara dari Gujarat, sebab secara politis tidak mungkin Gujarat menjadi sumber penyebaran Ketika itu, belum menjadi pusat perdagangan yang menghubungkan antara wilayah nusantara dengan wilayah timur tengah.

Keempat, teori yang menyatakan bahwa Islam datang dari sumber aslinya, yaitu arab. Sejarahwan asia tenggara yang menyatakan teori ini adalah naquib alattas. Teori ini beranggapan bahwa untuk melihat Islam di asia tenggara itu datang dari mana, maka yang harus dipertimbangkan adalah kajian terhadap teks-teks atau literatur Islam melayu Indonesia dan sejarah Panjang melayu terhadap berbagai istilah atau konsep kunci yang digunakan oleh para penulis Islam di asia tenggara pada abad ke -10-11 H/16-17 M. pendapat ini selarass dengan hasil kesimpulan seminar sejarah masuknya inslam di Indonesia di aceh, yang dinyatakan bahwa Islam datang ke Indonesia melalui saluran kangsung dari araba bad pertama hijriyah, dan daerah yang awalnya masuk Islam adalah aceh.

Dengan demikian para ahli sejarah sepakat bahwa Islam datang di jawa pada masa pemerintahan raja-raja hindu. Keberadaan Islam di jawa ditemukan dalam prassasti makam di laren gresik, yaitu Fatimah binti maimun, wafat tahun 
$1807 \mathrm{M}$, yang diidentifikasi sebagai keturunan nabi dan menjadi penyebar agama Islam di gresik. Prasasti ini menjadi bukti otentik bahwa Islam telah menyebar di jawa, khususnya di jawa timur pada masa pemerintahan raja hindu tepatnya raja airlangga. Jaringan perdagangan antara timur tengah dengan nusantara terjalin atas dasar relasi saling menguntungkan dengan mengambil jalur laut sehingga daerah pesisir jawa merupakan daerah yang lebih dahulu mengenal Islam.

Perkembangan Islam diluar jawa relative lebih cepat penyebarannya karena tidak banyak berhadapan dengan budaya-budaya lain, kecuali budaya hindu-budha. Di jawa, Islam menghadapi suasana yang kompleks dan halus, yang dipertahankan oleh para penguasa/raja. Oleh sebab itu, perkembangan Islam di tanah jawa menghadapi sua jenis lingkungan budaya, yaitu budaya lapisan petani atau lapisan bawah yang merupakan bagian kelompok terbesar yang masih dipengaruhi oleh urabay-dinamisme. Kemudian kebudayaan isstana yang merupakan tradisi agung dan menjadi unsur filsafat hindu-budha yang diperhalus budaya lapis atas.

Pemyebaran Islam di jawa untuk beberapa abad tidak mampu menembus benteng pengaruh kerajaan hindu yang kejawen. Penyebaran Islam harus merangkak dari kalangan bawah, yaitu ke daerah-daerah pedesaan sepanjang pesisir yang ada. Pada akhirnya penyebaran itu melahirkan komunitas baru yang berpusat di pesantren.

Sejak kerajaan jawa hindu majapahit $(1518 \mathrm{M})$ runtuh dan kerajaan Islam demak berdiri, makai slam dimulai sebagai kekuatan politik. Zaman peralihan tampak Ketika berdirinya kerajaan demak, yaitu peralihan dari zaman "kabudhan"(tradisi hindu budha) ke zaman "kawalen" (wali). Peralihan ini merupakan pengIslaman dan penyesuaian dengan suasana Islam, bukan berarti membuang budaya adiluhung zaman hindu budha. Peralihan ini menghasilkan bentuk berupa "sinkretisme" antara warisan budaya animism-dinamisme dan unsur-unsur Islam.

Dakwah Islam tampak dari interaksi dengan lingkungan sosial budaya setempat, berkembang dengan dua pendekatan, yakni pendekatan nonkompromis dan pendekatan kompromis. Yang dimaksud dengan pendekatan nonkompromis adalah dakwah ilam dengan tetap bertahan dengan identitas agama dan tidak mau menerima budaya luar kecuali budaya tersebut selaras dengan ajaran Islam. Pendekatan kompromis (akomodatif) merupakan suatu pendekatan yang berupaya menciptakan suasana damai, penuh toleransi, sedia hidup berdampingan dengan pengikut agama, dan tradisi lain yang berbeda tanpa mengorbankan agama dan tradisi agama masing-masing (cultural approach).

Dalam berdakwah, para wali tampaknya lebih memilih pendekatan kompromistik mengingat tradisi nenek moyang masyarakat jawa yang melatarbelakanginya. Para wali memulai dakwahnya di kalangan bawah melalui daerah pesisir yang jauh dari majapahit. Para wali dan masyarakat pedesaan 
membangun tradisi / budaya baru melalui pesantren sebagai basis kekuatan. Kekuatan yang dibangun ini akhirnya dapat menandingi kekuatan wibawa kebesaran kerajaan jawa hindu yang lambat laun semakin surut dan pada akhirnya runtuh.

Gambaran dari adanya akulturasi unsur Islam dan jawa pada akhirnya menciptakan budaya sintesis. Berikut ini adalah sebuah sintesis yang ada dalam kitab babad tanah djawi(sejarah tanah jawa).

'inilah sejarah kerajaan tanah jawa, mulai dari nabi adam yangberputrakan sis. Sis berputrakan nur-cahyo, nur-cahyo berputrakan nur-rassa, nur-rasa berputrakan sang hyang tunggal.....istana batara guru di sebut sura laya (nama taman_urabay hindu).'

Pada kutipan naskah babad tanah djawi tersebut, jelas terlihat adanya akulturasi timbal balik antara Islam dan budaya jawa dengan mengakomodir kepentingan masing-masing. Pada proses interaksi ini, masuknya Islam di jawa tidaklah membentuk komunitas baru yang sama sekali berbeda dengan masyarakat sebelumnya. Sebaliknya, Islam mencoba untuk masuk ke dalam struktur budaya jawa dan mengadakan penyaringan ajaran-ajaran kejawen dengan nuansa Islami.

Gambaran kehidupan manusia dalam menemukan tuhannya sering disimbolkan dengan pementasan wayang. Lakon yang biasanya ditampilkan merupakan ajaran -ajaran syariat untuk membawa penonton pada nuansa religious. Oleh sebab itu, wayang dianggap sebagai bagian dari acara religious untuk mengajarkan ajaran-ajaran ilahi. Seorang dalang diibaratkan sebagai tuhan yang dapat memainkan peran dan nasib orang (wayang). Penggambaran ini dimaknai secara ortodoks sebagai deskripsi puitis mengenai takdir.

Jika dilihat dari pengamalan ajaran-ajaran agama, masyarakat jawa terbagi menjadi dua , yaitu kelompok santri dan kelompok abangan. Kelompok yang perbuatannya didassarkan pada ajaran-ajaran agama merupakan kelompok santri sedangkan kelompok abangan masih mendasarkan panddangan dunianya pada tradisi hindu-budha atau kebudayaan jawa. Misalnya di jawa tengah bagian selatan pergulatan santri dan abangan justru didominasi oleh kelompok abangan. Contoh dari tradisi budaya jawa antara lain: selametan, yang merupakan tradisi turun temurun dari masyarakat jawa kuno dan hingga kini masih banyak dijumpai dalam kehidupan masyarakat jawa, kususnya masyarakat Yogyakarta adalah tradisi ruwatan, yang menarik dari tradisi ini yang pada awalnya berbau mistik, setelah terjadi akulturasi dengan ajaran Islam beralih menjadi bernuansa Islam. ${ }^{5}$

Setelah kekuasaan kerajaan hindu jawa majapahit hilang, pada seperempat abad ke 15 . pada zaman itu juga menandai berkuassanya sejumlah tokoh-tokoh muslim di bidang politik seperti ampel(Surabaya), gresik, tuban, demak, jepara, dan Cirebon. Meraka adalah pemimpin pertama "religious

5 Andik Wahyun Muqoyyidin, "Islam Jawa, Distingsi Tradisi, Transformasi Spirit Profetik, Dan Globalisasi," Akademika: Jurnal Pemikiran Islam 21, No. 1 (April 17, 2016): 110. 
politik" jawa Islam. Para tokoh agama/wali proses dakwahnya melalui pembauran dengan keluarga istana, melalui perkawinan atau keturunan.

Dengan demikian, kedatangan Islam membawa perubahan masyarakat atau pengalihan bentuk sosial menuju kea rah yang lebih baik. Misalnya sunan kalijaga dalam melakukan Islamisasi tanah jawa menggunakan pendekatan budaya, yakni menggunakan seni pewayangan untuk menentang feodalisme kerajaan majapahit. Dalam seni pewayangan ia berusaha menggunakan unsurunsur local sebagai media dakwahnya dengan mengadakan perubahanperubahan lakon juga fisik dan alat-alatnya. Kepandaian sunan kalijaga dalam berkreasi wayang pada akhirnya dapat menarik masyarakat untuk datang melihat pertunjukkan wayang tersebut, sehingga pada akhirnya mereka mau memeluk agama Islam berkat syarat yang dianjurkan oleh sunan kalijaga yaitu dengan mengucapkan dua kalimat syahadat. Cara ini merupakan strategi sunan kalijaga dalam menjalankan misinya untuk berdakwah dengan perantara kesenian wayang. Dengan cara tersebut dakwah yang disampaikan oleh sunan kalijaga dapat diterima semua pihak. Metode dakwah dengan cara ini sepertinya cukup efektif sehingga Islam bida tersebar secara luas karena pada dasarnya Islam mampu menunjukkan wajah Islam yang akomodatif. 6 Menurut babad janah djawi , penyebaran agama Islam dijawa dilakukan oleh walisongo, yakni para wali yang berjumlah Sembilan orang : 1. Maulana malik ibrahin (sunan gresik), 2. Raden rahmat (sunan ampel)_urabaya, 3. Makdhun Ibrahim (sunan bonang), 4. Sunan drajat, 5. Sunan giri atau raden paku yang mengarang nyanyian asmarandana, 6. Sunan kudus atau ja'far shadiq, 7. Sunan muria atau raden prawoto yang menggubah lagu-lagu jawa seperti sinom atau kinanthi, 8 . Sunan gunung jati atau syarif hidayatulah, 9. Sunan kalijaga atau raden syahid. Mulai saat itulah, ada proses peralihan dari zaman hindu-budha berpindah menjadi zaman para wali(zaman kejawen). ${ }^{7}$

\section{Model Budaya Pada Produk Dakwah}

Model budaya pada produk dakwah diantaranya sebagai berikut:

a. Budaya lokal dapat menentukan keoptimalan keberhasilan dakwah.

b. Budaya lokal dapat mendukung tingkat ketepatan produk dakwah sesuai dengan tuntutan mendesak masyarakat mad'u yang dihadapinya.

c. Budaya lokal bahkan turut menentukan tingkat kepuasan masyarakat atas produk suatu kegiatan dakwah Ketika ia melibatkan pertimbangan budaya lokal.

6 Nor Kholis, "Syiar Melalui Syair (Eksistensi Kesenian Tradisional Sebagai Media Dakwah Di Era Budaya Populer)," Al-Balagh: Jurnal Dakwah Dan Komunikasi 3, No. 1 (2018): 109.

7 Sulkhan Chakim, "Dakwah Clan Dialektika Budaya Jawa Dalam Lintasan Sejarah," Komunika: Jurnal Dakwah Dan Komunikasi 2, $\quad$ No. 1 (2008): 51, Https://Doi.Org/10.24090/Komunika.V2i1.809. 
d. Budaya lokal dapat mendorong tindak lanjut pengamalan pesan-pesan dakwah itu sendiri oleh masyarakat, sehingga suatu kegiatan dakwah memberikan manfaat praktis dan dakwah tidak terhenti sebatas kegiatan seremonial belaka yang tanpa kegunaan nyata bagi masyarakat.

e. Frekuensi dan intensitas dakwah itu sendiri bisa meningkat dengan motivasi sosial yang tumbuh dari perlibatan budaya lokal. ${ }^{8}$

\section{Simpulan}

Dalam penjelasan diatas dapat disimpulkan. Sebelum Islam datang ke Indonesia, masyarakat Indonesia masih mempercayai animism-dinamisme sehingga tradisi masih melekat pada masyarakat khususnya masyarakat jawa. Kebudayaan jawa terbagi atas tiga fase yakni : fase kebudayaan jawa pra hindubudha, fase kebudayaan masa hindu-budha dan fase penyebaran dan pelembagaan dakwah di jawa. Pada fase terakhir ini Islam mulai masuk, sehingga para wali mencari strategi untuk menyebarluaskan Islam di tanah jawa. Kemudian mereka menggunakan strategi dakwah melalui perantara kebudayaan yaitu media pewayangan, ternyata cukup signifikan sehingga dapat menarik masyarakat untuk memeluk agama Islam. Karena berdakwah menggunakan media kebudayaan ini dapat diterima oleh semua pihak sehingga Islam berkembang pesan dan dapat disebarluaskan.

\section{Referensi:}

Al-Amri, Limyah, and Muhammad Haramain. "Akulturasi Islam Dalam Budaya Lokal." Kuriositas: Media Komunikasi Sosial Dan Keagamaan 10, no. 2 (November 24, 2017): 87-100. https://doi.org/10.35905/kur.v10i2.594.

Arifani, Moch Anif. "Model Pengembangan Dakwah Berbasis Budaya Lokal." Ilmu Dakwah: Academic Journal for Homiletic Studies 5, no. 15 (2010): 849-78. https:// doi.org/10.15575/idajhs.v5i15.425.

Bauto, Laode Monto. "Perspektif Agama Dan Kebudayaan Dalam Kehidupan Masyarakat Indonesia (Suatu Tinjauan Sosiologi Agama)." Jurnal Pendidikan Ilmu Sosial 23, no. 2 (2014): 11-25. https:// doi.org/10.17509/jpis.v23i2.1616.

Chakim, Sulkhan. "Dakwah clan Dialektika Budaya Jawa dalam lintasan Sejarah." KOMUNIKA: Jurnal Dakwah dan Komunikasi 2, no. 1 (2008): 4253. https://doi.org/10.24090/komunika.v2i1.809.

Kholis, Nor. "Syiar Melalui Syair (Eksistensi Kesenian Tradisional Sebagai Media Dakwah Di Era Budaya Populer)." Al-Balagh: Jurnal Dakwah Dan Komunikasi 3, no. 1 (2018): 103-125.

${ }^{8}$ Moch Anif Arifani, "Model Pengembangan Dakwah Berbasis Budaya Lokal," Ilmu Dakwah: Academic Journal For Homiletic Studies 5, No. 15 (2010): 861, Https://Doi.Org/10.15575/Idajhs.V5i15.425. 
Muqoyyidin, Andik Wahyun. "Islam Jawa, Distingsi Tradisi, Transformasi Spirit Profetik, Dan Globalisasi." Akademika: Jurnal Pemikiran Islam 21, no. 1 (April 17, 2016): 99-116.

Purwaningrum, Septiana, and Habib Ismail. “Akulturasi Islam Dengan Budaya Jawa: Studi Folkloris Tradisi Telonan Dan Tingkeban Di Kediri Jawa Timur." Fikri: Jurnal Kajian Agama, Sosial Dan Budaya 4, no. 1 (June 14, 2019): 31-42. https:/ / doi.org/10.25217/jf.v4i1.476.

Syarifah, Masykurotus. "Budaya dan Kearifan Dakwah." al-Balagh: Jurnal Dakwah dan Komunikasi 1, no. 1 (June 8, 2016): 23-38. https:// doi.org/10.22515/balagh.v1i1.43. 